\title{
Anticorrosive ability of electrochemically synthesized 2,2'-disulfanediyldianiline for mild steel corrosion: electrochemical and thermodynamic studies
}

\author{
M. R. Vinutha ${ }^{1} \cdot$ T. V. Venkatesha ${ }^{1} \cdot$ C. Nagaraja ${ }^{1}$
}

Received: 2 November 2017 / Accepted: 2 June 2018 / Published online: 12 June 2018

(c) The Author(s) 2018

\begin{abstract}
The corrosion inhibition property of electrochemically synthesized 2,2'-disulfanediyldianiline compound was investigated for mild steel in $1 \mathrm{M} \mathrm{HCl}$ using electrochemical and weight loss techniques. The morphology of steel surface was examined using SEM and optical microscopy. Thermodynamic parameters were determined and discussed. To study the effect of the molecular structure of inhibitor on its inhibitive performance, quantum chemical studies were performed using density functional theory by B3LYP/6-311G (d,p) basis set. The theoretical studies depicted $-\mathrm{N}$ and $-\mathrm{S}$ atoms as the adsorption centers in molecule.
\end{abstract}

\section{Graphical abstract}

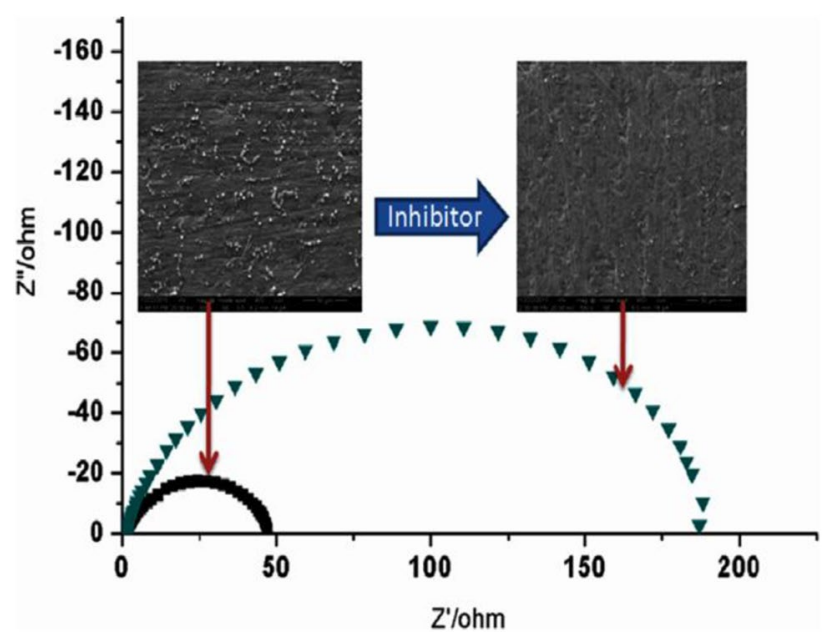

Keywords Disulfide $\cdot$ DFT $\cdot$ Inhibitor $\cdot$ Thermodynamic parameters

Electronic supplementary material The online version of this article (https://doi.org/10.1007/s40090-018-0149-0) contains supplementary material, which is available to authorized users.

T. V. Venkatesha

drtvvenkatesha@yahoo.co.uk

1 Department of Chemistry, School of Chemical Sciences, Jnana Sahyadri Campus, Kuvempu University, Shankaraghatta, Karnataka 577451, India

\section{Introduction}

In several industries, acid solutions are used for the processes like pickling, de-scaling, for removing rust and scale from alloy surface. The aggressive nature of acid causes dissolution of material during the course of cleaning process which leads to material loss [1-3]. The most effective approach to minimize this material loss is, use of organic 
compounds as a corrosion inhibitor in acid solution. A large number of chemical compounds, containing a heteroatom in their ring and presence of an electron-rich center have served for the purpose [4-9]. Even though inhibitors are efficient in preventing corrosion, the toxicity of a few organic compounds causes some serious repercussions on the environment. Nowadays, researchers use drug molecules and plant extracts as eco-friendly inhibitor [10-15]. In this concern, 2,2'-disulfanediyldianiline (DSA) compound is synthesized by electrochemical method. In most of chemical synthesis of DSA is done by oxidation of suitable thiols. To serve for this purpose, reagents such as $\mathrm{H}_{2} \mathrm{O}_{2}, \mathrm{MoO}_{2} \mathrm{Cl}_{2}$, metal halides and metals with exchange resin are used [16-20]. The disadvantages of these methods are a very time-consuming process and required maintenance of drastic conditions (either very high temperature or low temperature below zero degrees centigrade). These process also suffered by reduced yield of required products, metal contamination, toxicity, etc. In addition, maintenance of stoichiometric ratio of the reagents is necessary to bring about successful oxidation process. The electrochemical processes generally produces less byproduct compared to chemical processes as it is carried out at particular potential value (oxidising/reducing). Electrons are environmentally friendly, in comparison to chemical reagents. Further, the electrochemical processes are characterised by lower temperature, less degradation of product, high energy efficiency, a fewer processing steps, product selectivity through the control of oxidation/reduction potential. That is how we have chosen a green synthesis of 2, 2'-disulfanediyldianiline (DSA) via electrochemical methods. There is no reported literature available, on the use of 2, 2'-disulfanediyldianiline (DSA) as a corrosion inhibitor for mild steel in $\mathrm{HCl}$ media. The scope of this work is to study the effect of DSA compound on corrosion of mild steel in $1 \mathrm{M} \mathrm{HCl}$ solution. The quantum chemical calculations are performed to support our experimental findings and to assign suitable mechanism for DSA adsorption.

\section{Experiments}

\section{Cyclic voltammetric studies}

Cyclic voltammetry and preparative electrolysis were performed using CHI 660C work station of USA make. In the voltammetry experiments, a polished glassy carbon disc electrode ( $3 \mathrm{~mm}$ diameter) with alumina powder and platinum wire were used as working electrode and counter electrode, respectively. In the preparative experiments, an assembly of two carbon rods ( $4 \mathrm{~cm}$ length and $1 \mathrm{~cm}$ diameter) and large copper plate (area $9 \mathrm{~cm}^{2}$ ) were used as working and counter electrodes, respectively. The working electrode potential was measured vs saturated calomel electrode (SCE) and all experiments were carried out at room temperature. 2-amino thiophenol, phosphate salts were of pro-analysis grade from SD fine chemicals and used as such without any further purification.

\section{Electro-organic synthesis of 2, 2'-disulfanediyldianiline}

In a typical procedure, $80 \mathrm{~mL}$ of phosphate buffer solution $(c=0.2 \mathrm{M}, \mathrm{pH} 7.5)$ in $70: 30(\mathrm{v} / \mathrm{v})$ ethanol/water was preelectrolyzed at $0.75 \mathrm{~V}$ vs. SCE in an undivided cell equipped with magnetic stirrer, followed by the addition of $2 \mathrm{mM}$ 2 -aminothiophenol. The electrolysis was terminated when the decay of the current became more than $95 \%$ of its initial value. After the electrolysis, a few drops of acetic acid were added to the solution and the cell was left overnight. The ethanol was distilled off under reduced pressure; precipitated product was collected by filtration and washed several times with distilled water. The crude samples were recrystallized from the water-ethanol mixture and subjected to characterization by NMR, Mass, IR and UV-visible spectroscopy.

\section{Characteristics of product DSA $\left(\mathrm{C}_{12} \mathrm{H}_{12} \mathrm{~N}_{2} \mathrm{~S}_{2}\right)$}

Isolated yield: $77 \%,{ }^{1} \mathrm{H}$ NMR (400 MHz, DMSO- $\left.d_{6}\right) \delta=5.45$ (s, 4H, $\left.\mathrm{NH}_{2}\right), 6.43$ (d, 2H, Ar,), 6.73 (d, 2H, Ar), 6.99 (m, $4 \mathrm{H}, \mathrm{Ar})$. IR (KBr) $\nu=3378,3298,3181,3063,3013,1613$, 1470, 1441, 1303, 1243, 1152, 856, $751 \mathrm{~cm}^{-1}$.MS (EI, $70 \mathrm{eV}, \mathrm{m} / \mathrm{z}$ ) (relative intensity): $249\left(\mathrm{M}^{+}, 100\right)$.

\section{Mild steel sample}

The mild steel specimens (sheet) of compositions of $0.41 \%$ C, $0.46 \% \mathrm{Mn}, 0.24 \% \mathrm{~S}, 0.22 \% \mathrm{Si}, 0.17 \% \mathrm{Al}$ and remaining is of Fe were used. The steel coupons of dimension $4 \mathrm{~cm} \times 2 \mathrm{~cm} \times 0.2 \mathrm{~cm}$ were chosen for weight loss experiment.

\section{Solutions}

The test solution was $1 \mathrm{M} \mathrm{HCl}$ prepared and a disulfide solution $(1 \mathrm{mM})$ was prepared using 1:50 (v/v) of DMF/Millipore water. Different concentrations of disulfide solutions $(0.01,0.03$ and $0.05 \mathrm{mM})$ were prepared using $1 \mathrm{M} \mathrm{HCl}$.

\section{Electrochemical measurements}

Electrochemical data were recorded using $\mathrm{CHI}$ 660C electrochemical analyzer. Mild steel specimen with $1 \mathrm{~cm}^{2}$ exposed areas was used as working electrode. The platinum electrode and SCE were used as counter and reference electrode, respectively. Prior to polarization and electrochemical 
impedance spectroscopic measurements (EIS), a steady-state open-circuit potential (OCP) was measured.

EIS measurements were done at OCP in the frequency range $0.01 \mathrm{~Hz}$ to $100 \mathrm{kHz}$ with an amplitude of $5 \mathrm{mV}$. The inhibition efficiency of EIS measurement was calculated using charge transfer resistance $\left(R_{\mathrm{ct}}\right)$ values using the following equation

$\eta_{\mathrm{EIS}}(\%)=\frac{R_{\mathrm{ct}}-R_{\mathrm{ct}}^{0}}{R_{\mathrm{ct}}} \times 100$

where $R_{\mathrm{ct}}$ and $R_{\mathrm{ct}}^{0}$ are charge transfer resistance of working electrode with and without inhibitor, respectively.

Polarization plots were generated in the potential range + 300 to $-300 \mathrm{mV}$ with a scan rate of $10 \mathrm{mV} / \mathrm{S}$. The corrosion current density $\left(I_{\text {corr }}\right)$, equilibrium potential $\left(E_{\text {corr }}\right)$, cathodic $\left(\beta_{\mathrm{c}}\right)$ and anodic $\left(\beta_{\mathrm{a}}\right)$ Tafel slopes were found. The inhibition efficiency was calculated using $I_{\text {corr }}$ value by the equation

$\eta_{\mathrm{P}}(\%)=\frac{I_{\text {corr }}^{0}-I_{\text {corr }}}{I_{\text {corr }}^{0}} \times 100$

where $I_{\text {corr }}^{0}$ and $I_{\text {corr }}$ are corrosion current density in absence and in presence of inhibitor, respectively.

\section{Weight loss measurements}

Weight loss measurements carried out by weighing mild steel specimens before and after its immersion in $100 \mathrm{~mL}$ of $1 \mathrm{M} \mathrm{HCl}$ and also in $1 \mathrm{M} \mathrm{HCl}$ containing different amount of DSA. All experiments were performed at atmospheric ambient and at temperature range of 303-333 K. The corrosion rate and inhibition efficiency (IE\%) were calculated using the following equation.

$\nu_{\text {corr }}=\frac{\Delta m}{S t}$

$\eta_{\mathrm{w}} \%=\frac{\nu_{\text {corr }}^{0}-v_{\text {corr }}}{\nu_{\text {corr }}^{0}} \times 100$

\section{Morphological studies}

Surface morphology of mild steel samples after the corrosion experiment was investigated using scanning electron microscopy (SEM) and optical microscopy.

\section{Quantum chemical studies}

Quantum chemical calculations were performed using PCgamess (firefly 8.1.1 version) software [21, 22] by DFT method using B3LYP/6-311 G(d,p) basis set.

\section{Results and discussion}

\section{Cyclic voltammetric studies}

The cyclic voltammogram (Fig. 1) of 2-aminothiophenol in water (Phosphate buffer of $C=2 \mathrm{mM}$; $\mathrm{pH}$ 7.5)/ethanol mixture $(30: 70, v / v)$ shows two anodic peaks $\mathrm{A} 1$ and $\mathrm{A} 2 \mathrm{vs}$ SCE. The anodic peaks A1 and A2 at -0.025 and $0.75 \mathrm{~V}$ corresponds to one and two electron oxidation of 2-aminothiophenol, respectively [23]. The absence of cathodic peak indicated that, the oxidation of 2-aminothiophenol is irreversible in nature.

The cyclic voltammogram of DSA showed a single anodic peak B1 at $1.1 \mathrm{~V}$ vs SCE which is higher than peaks A1 and A2. Further product formation was confirmed by ${ }^{1} \mathrm{H}$ NMR, mass, FT-IR and UV-visible spectral data. In $1 \mathrm{H}$ NMR of the product (S1) singlet peak at $\delta=5.45$ corresponds to $-\mathrm{NH}$ protons, which shows symmetric stretching at $3378.06 \mathrm{~cm}^{-1}$ and asymmetric stretching at $3298.07 \mathrm{~cm}^{-1}$ in FT-IR spectrum of the product. This inferred that, amino group was not involved in the oxidation process (Fig. 2).

There is no characteristic peak at $2550 \mathrm{~cm}^{-1}$ in FT-IR and also there is no peak which corresponds to $-\mathrm{SH}$ proton in $1 \mathrm{H}$ NMR spectrum of the product, this inferred the participation of -SH group in dimerization. UV-visible spectra of both 2-aminothiophenol and the product were recorded in ethyl acetate (Fig. 3). The $\lambda_{\max }$ of DSA appeared at a higher wavelength than that of 2-aminothiophenol. The reaction pathway adopted for the synthesis of product is described in Scheme 1.

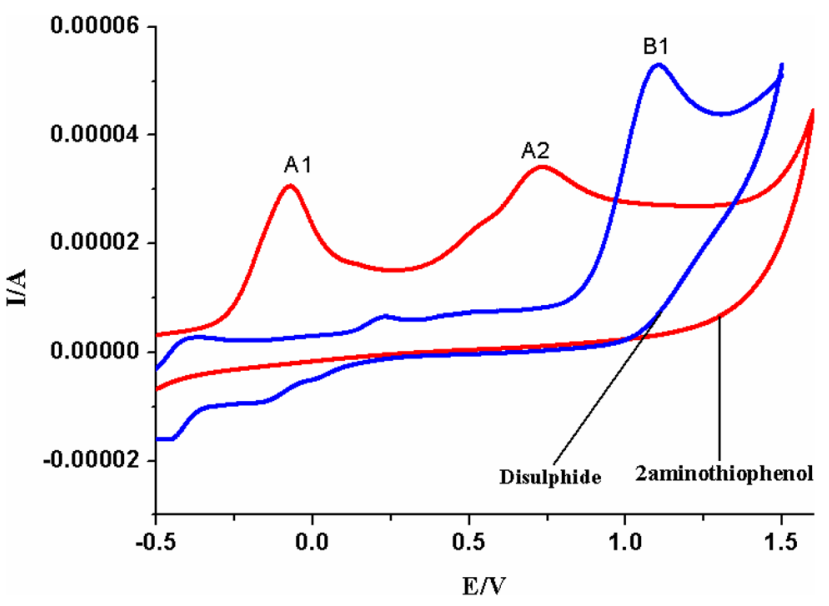

Fig. 1 Cyclic voltamogram of 2-aminothiophenol and product disulfide 


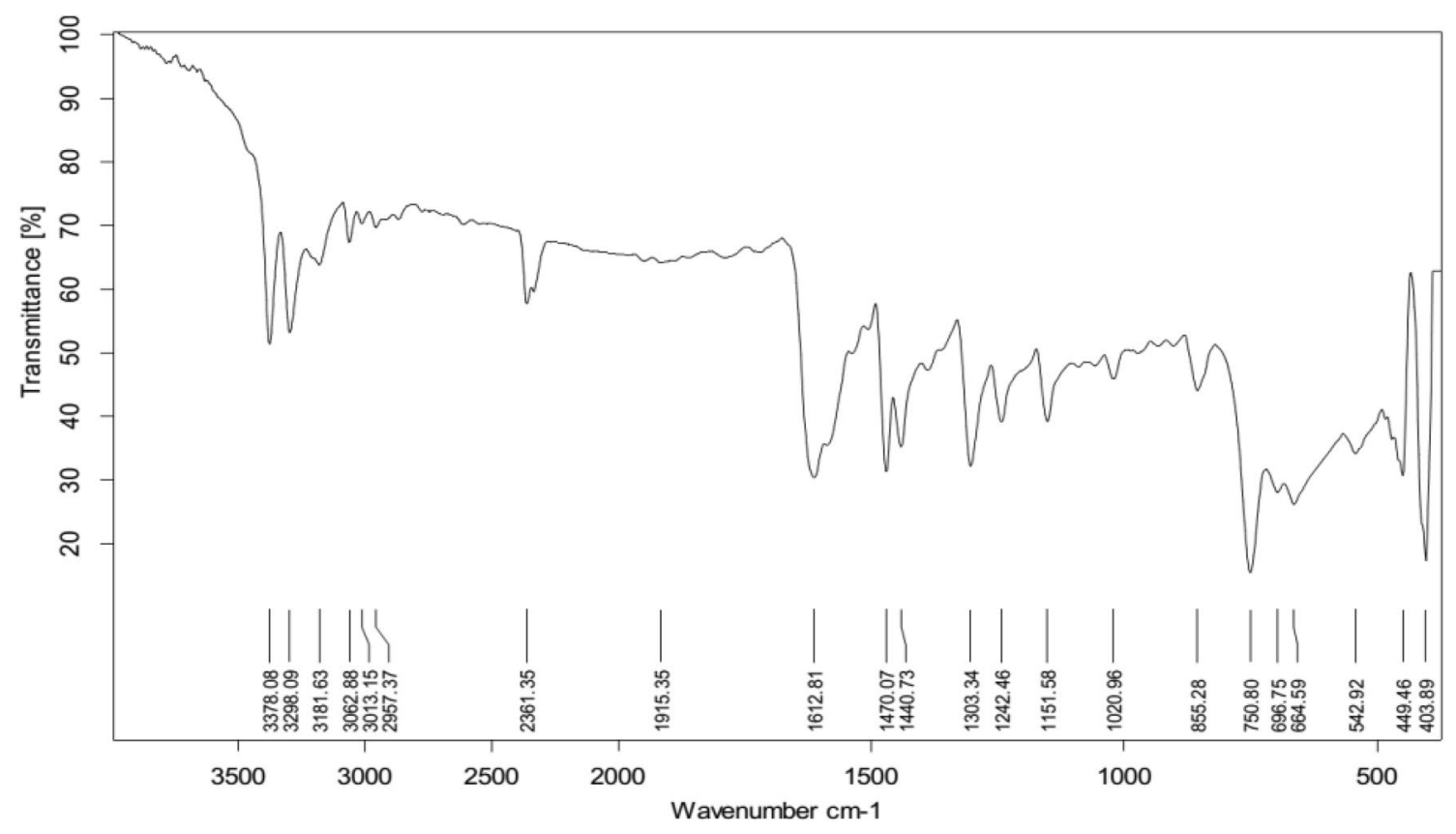

Fig. 2 FT-IR spectra of disulfide compound

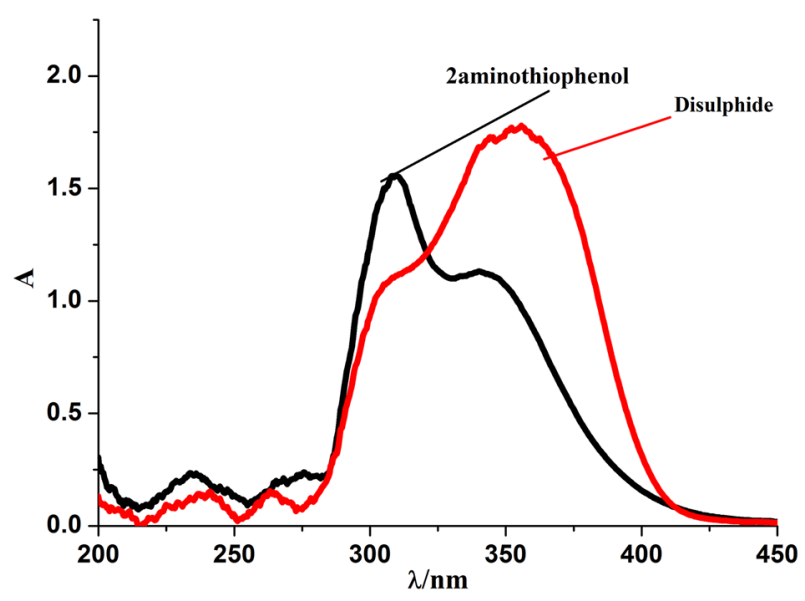

Fig. 3 UV-visible spectra of 2-aminothiophenol and disulfide

2<smiles>Nc1ccccc1S</smiles>

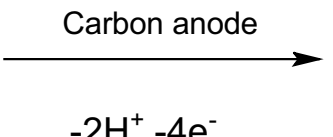

$-2 \mathrm{H}^{+},-4 \mathrm{e}^{-}$

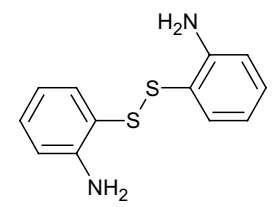

Scheme 1 Schematic representation synthesis of disulfide compound

\section{Polarization studies}

Figure 4 shows the typical polarization curves for MS in $1 \mathrm{M} \mathrm{HCl}$ generated from the test solution without and with

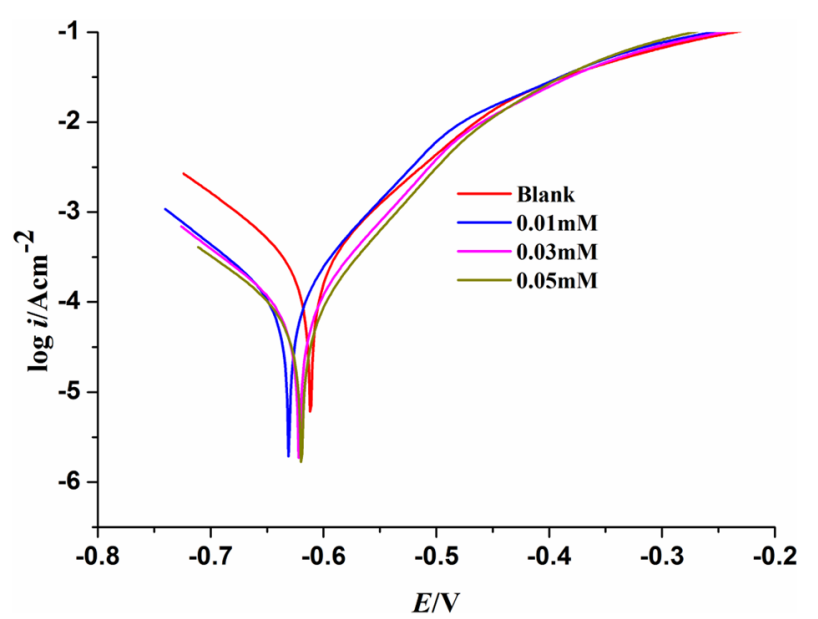

Fig. 4 Polarization curves in $1 \mathrm{M} \mathrm{HCl}$ in the absence and presence of disulfide

different concentration of DSA. As seen from the Fig. 4, there is no observable change in the nature of the curves for $1 \mathrm{M} \mathrm{HCl}$ solution and solution with different disulfide concentration. The corrosion potential $\left(E_{\text {corr }}\right)$, corrosion current density $\left(I_{\text {corr }}\right)$, cathodic and anodic Tafel slopes $\left(\beta_{\mathrm{a}}, \beta_{\mathrm{c}}\right)$ and inhibition efficiency were presented in Table 1 . From Table 1 , we can observe a minor shift in both cathodic $\left(\beta_{\mathrm{c}}\right)$ and anodic $\left(\beta_{\mathrm{a}}\right)$ slope values. The $E_{\mathrm{corr}}$ of uninhibited and inhibited solution remains very close to each other and $\Delta E_{\text {corr }}$ value found to be around $10 \mathrm{mV}$ only. From these factors, it inferred that, DSA acts as mixed type inhibitor, 
Table 1 Polarisation parameters for different disulfide concentration at temperature: $303 \mathrm{~K}$

\begin{tabular}{lllllc}
\hline$C / \mathrm{mM}$ & $-E_{\text {corr }} / \mathrm{mV}$ & $\begin{array}{l}\beta_{\mathrm{c}} l \\
\mathrm{mV} \mathrm{dec}^{-1}\end{array}$ & $\begin{array}{l}\beta_{\mathrm{a}} \mathrm{mV} \mathrm{dec}^{-1} \\
\mathrm{mV} \mathrm{corr}^{\prime}\end{array}$ & $\begin{array}{l}I_{\text {corl }} \\
\mu \mathrm{cm}^{-2}\end{array}$ & $\mathrm{IE} / \%$ \\
\hline 0.00 & 612 & 108.8 & 91.6 & 285.4 & - \\
0.01 & 614 & 117.6 & 82.2 & 114.0 & 60.05 \\
0.03 & 622 & 106.2 & 72.1 & 86.4 & 69.72 \\
0.05 & 620 & 112.7 & 71.1 & 71.9 & 74.81 \\
\hline
\end{tabular}

which controls both anodic and cathodic reaction [24]. The corrosion current density $\left(I_{\text {corr }}\right)$ value decreases with the increase of inhibitor concentration, indicating the inhibitor controls the charge-transfer reactions occurring on the metal surface [25]. Thus, DSA protects the steel from corrosion by controlling both anodic and cathodic charge transfer process.

\section{Electrochemical impedance studies}

The inhibitive effect of DSA on MS corrosion in $1 \mathrm{M} \mathrm{HCl}$ solution was investigated using electrochemical impedance spectroscopy (EIS). The EIS data were analyzed using Zsimwin-3.21 software and the so obtained EIS parameters were tabulated in Table 2. The Nyquist and Bode plots are defined in Figs. 5 and 6, respectively. The Nyquist plots (Fig. 5) are semicircle, which indicates corrosion process is controlled by transfer of charges [26]. At higher frequency, nature of Nyquist plot in all concentration is exhibiting same behavior, which is related to oxidation of metal or its oxides (hydroxides) at the metal/solution interface. A small inductive loop observed at low frequency is attributed to the relaxation process obtained by the adsorption of inhibitor molecule on electrode surface or adsorption of species such as $\left(\mathrm{FeCl}^{-}\right)_{\mathrm{ads}}$ or $\left(\mathrm{FeCl}^{-} \mathrm{Inh}^{+}\right)_{\text {ads }}$ [27] or it may also due to re-dissolution of adsorbed species [28].

In Nyquist plot, (Fig. 5) the diameter of semicircle increases with increase in DSA concentrations represents a decrease in the rate of charge transfer process and thus minimizes the corrosion rate. The shape of the semicircle is almost same at all disulfide concentrations, suggesting a mechanism of inhibition remains same for all inhibitor concentration. The semicircles are depressed at the center

Table 2 EIS parameters for different disulfide concentration measured at $303 \mathrm{~K}$

\begin{tabular}{llllll}
\hline$C / \mathrm{mM}$ & $R_{\mathrm{cl}} / \Omega \mathrm{cm}^{-2}$ & $Q / S^{\mathrm{n}} \Omega^{-1} \mathrm{~cm}^{-2}$ & $\mathrm{~N}$ & $C_{\mathrm{dl}} / \mu \mathrm{F} \mathrm{cm}{ }^{-2}$ & $\mathrm{IE} / \%$ \\
\hline 0 & 46.94 & $1.953 \times 10^{-4}$ & 0.8398 & 462.4 & - \\
0.01 & 123.3 & $1.666 \times 10^{-4}$ & 0.8797 & 345 & 61.93 \\
0.03 & 164.6 & $1.291 \times 10^{-4}$ & 0.8741 & 279.3 & 71.48 \\
0.05 & 182.8 & $1.41 \times 10^{-4}$ & 0.8987 & 263.6 & 74.32 \\
\hline
\end{tabular}

towards the real axis due to frequency dispersion resulted from the heterogeneity of the MS surface [28].

The analysis of complex plane plots is done by fitting the experimental findings to the equivalent circuit (shown in Fig. 5), to obtain accurate results. The circuit consists of an inductor $(L)$, solution resistance $\left(R_{\mathrm{S}}\right)$ in series with the parallel combination of charge-transfer resistance $\left(R_{\mathrm{ct}}\right)$ and a constant phase element Q (CPE). The impedance spectra exhibit single slightly depressed semicircle, as a result of this the MS-solution interface does not behave as an ideal capacitor. In the case of non-ideal capacitive behavior of double layer, the constant phase element (CPE) is used in place of pure capacitor [29]. The impedance of the CPE is given by

$Z_{\mathrm{CPE}}=Y_{0}^{-1}(j \omega)^{-\mathrm{n}}$

where $Y_{0}$ is the magnitude of the CPE, $j$ is the imaginary unit, $\omega$ is the angular frequency and $\mathrm{n}$ is CPE exponent which used to assess the surface inhomogeneity, resulting from surface roughness, inhibitor adsorption, porous layer formation, etc. [30]. The capacitance $\left(C_{\mathrm{dl}}\right)$ of CPE is calculated using the following relation:

$C_{\mathrm{dl}}=\left(Q R_{\mathrm{ct}}^{1-n}\right)^{1 / n}$

Bode phase angle plots account for the double-layer capacitance and charge-transfer phenomena, whereas Bode magnitude plots describe the degree of homogeneity of MS surface (Fig. 6). There is a significant shift in the slope from -1 and deviations in the phase angle from $90^{\circ}$. The maximum angle obtained at the measured frequency range corresponds to the formation of an adsorptive layer of DSA on MS [31]. In Bode plots (Fig. 6), there is increase in the phase angle with increase in DSA concentration can be account

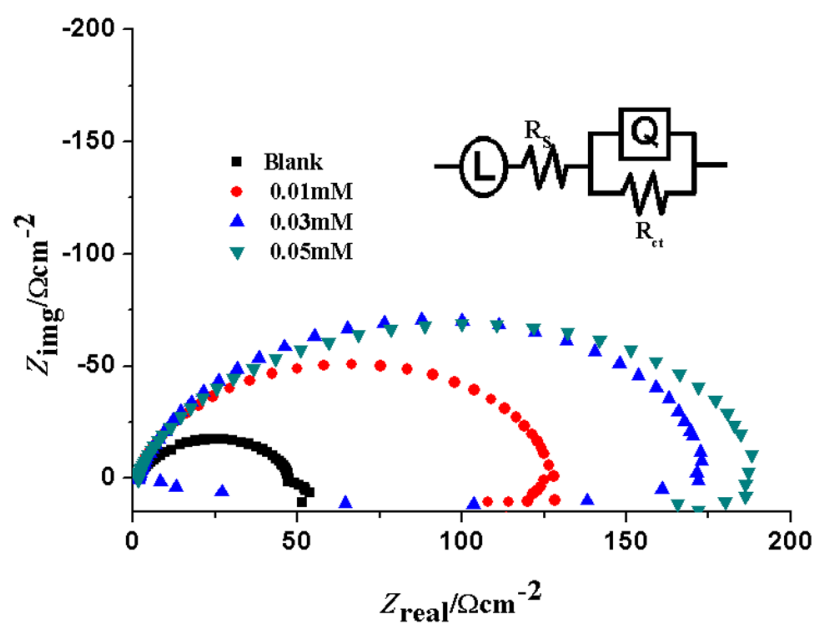

Fig. 5 Nyquist plots in $1 \mathrm{M} \mathrm{HCl}$ in the absence and presence of disulfide 

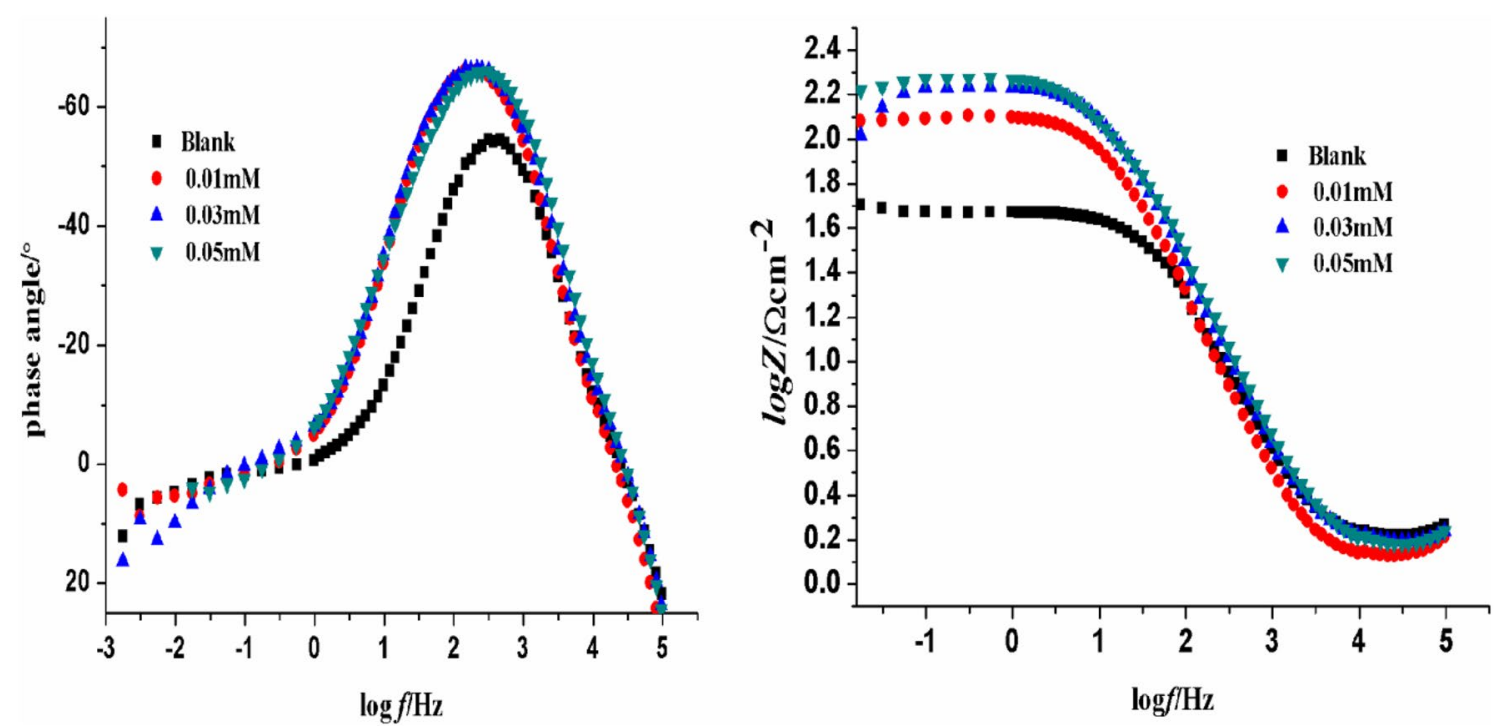

Fig. 6 Electrochemical impedance spectra in $1 \mathrm{M} \mathrm{HCl}$ in the absence and presence of disulfide: Bode modulus and Bode phase angle plots

Table 3 Corrosion rate and the inhibition efficiency as measured by weight loss method

\begin{tabular}{|c|c|c|c|c|c|c|c|c|}
\hline \multirow[t]{3}{*}{$C(\mathrm{mM})$} & \multicolumn{8}{|l|}{ Temperature } \\
\hline & \multicolumn{2}{|l|}{$303 \mathrm{~K}$} & \multicolumn{2}{|l|}{$313 \mathrm{~K}$} & \multicolumn{2}{|l|}{$323 \mathrm{~K}$} & \multicolumn{2}{|l|}{$333 \mathrm{~K}$} \\
\hline & $\begin{array}{l}\nu_{\text {corr }} \\
\left(\mathrm{mg} \mathrm{cm}^{-2} \mathrm{~h}^{-1}\right)\end{array}$ & IE (\%) & $\begin{array}{l}\nu_{\text {corr }} \\
\left(\mathrm{mg} \mathrm{cm}^{-2} \mathrm{~h}^{-1}\right)\end{array}$ & IE $(\%)$ & $\begin{array}{l}\nu_{\text {corr }} \\
\left(\mathrm{mg} \mathrm{cm}^{-2} \mathrm{~h}^{-1}\right)\end{array}$ & IE $(\%)$ & $\begin{array}{l}\nu_{\text {corr }} \\
\left(\mathrm{mg} \mathrm{cm}^{-2} \mathrm{~h}^{-1}\right)\end{array}$ & $\operatorname{IE}(\%)$ \\
\hline Blank & 0.76 & - & 0.89 & - & 1.10 & - & 4.56 & - \\
\hline 0.01 & 0.29 & 62 & 0.50 & 44 & 0.81 & 26 & 4.02 & 12 \\
\hline 0.03 & 0.23 & 70 & 0.37 & 58 & 0.62 & 44 & 3.57 & 22 \\
\hline 0.05 & 0.18 & 76 & 0.27 & 70 & 0.46 & 58 & 3.11 & 32 \\
\hline
\end{tabular}

for the anticorrosive effect of DSA. In addition, increase in the charge transfer resistance $\left(R_{\mathrm{ct}}\right)$ and decrease in the capacitance $\left(C_{\mathrm{dl}}\right)$ values confirm the adsorption of inhibitor on steel surface.

\section{Weight loss studies}

The weight loss data generated for different DSA concentrations at temperature range of $303-333 \mathrm{~K}$ were listed in Table 3. The corrosion inhibition efficiency increases with increasing inhibitor concentrations and decreases with rise in temperature (Fig. 7).

\section{Adsorption and thermodynamic study}

DSA molecule has a polar amine group, sulfur atoms, and $\pi$ electrons, which facilitates its interaction with the metal atoms and thus its adsorption on metal surface. During the process of adsorption it is accepted that, the inhibitor molecules displace the adsorbed water molecules at the metal surface. This displacement of water molecule can be represented as follows:

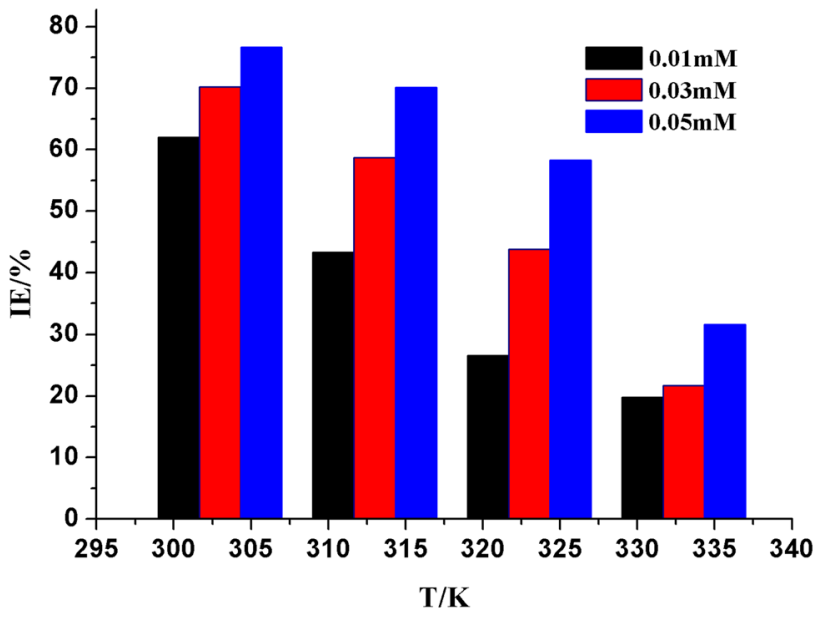

Fig. 7 Variation of inhibition efficiency measured for different DSA concentrations at temperature range of 303-333 K

$\operatorname{Org}_{(\mathrm{sol})}+x \mathrm{H}_{2} \mathrm{O}_{(\mathrm{ads})} \leftrightarrow \operatorname{Org}_{(\mathrm{ads})}+x \mathrm{H}_{2} \mathrm{O}_{(\mathrm{sol})}$ 
where $x$ is the number of water molecules displaced by one molecule of an organic inhibitor. The adsorption isotherm provides basic information regarding the interaction between inhibitor and mild steel surface. The most frequently used adsorption isotherms are Langmuir, Temkin, and Frumkin [32].In the present case, it followed Langmuir adsorption isotherm (as in Figs. 8, 9). The Langmuir adsorption isotherm is

$\frac{C}{\theta}=\frac{1}{K_{\mathrm{ads}}}+C$

where $C$ is a concentration of inhibitor, $\theta$ is surface coverage and $K_{\text {ads }}$ adsorption equilibrium constant. The value $K_{\text {ads }}$ represents the strength of bond between adsorbate and adsorbent.

Large values of $K_{\text {ads }}$ indicate that, inhibitor is strongly bound to the metal surface and hence has better inhibition efficiency. The value of $K_{\text {ads }}$ decreases with rise in temperature of the solution is due to thermal agitation of inhibitor molecules [33]. From the $K_{\text {ads }}$ values, the $\Delta G_{\text {ads }}$ are calculated using

$\Delta G_{\text {ads }}=-R T \ln \left(55.5 K_{\text {ads }}\right)$

where 55.5 is the molar concentration of water in the solution $T$, is a absolute temperature and $R$, is a universal gas constant. The negative values of $\Delta G_{\text {ads }}$ describe the spontaneity of an adsorption process and stability of a inhibitor film/layer on the steel surface. The $\Delta G_{\text {ads }}$ values above $-40 \mathrm{~kJ} \mathrm{~mol}^{-1}$ were reported as chemisorption, which occurs either by sharing of electron/charge or by transfer from the inhibitor molecules to the metal surface to forms a covalent bond [34].

In present study, the $\Delta G_{\text {ads }}$ values from all the three methods at $303 \mathrm{~K}$ are around $40 \mathrm{~kJ} \mathrm{~mol}^{-1}$, as temperature increases the $\Delta G_{\text {ads }}$ values decreases and are in between

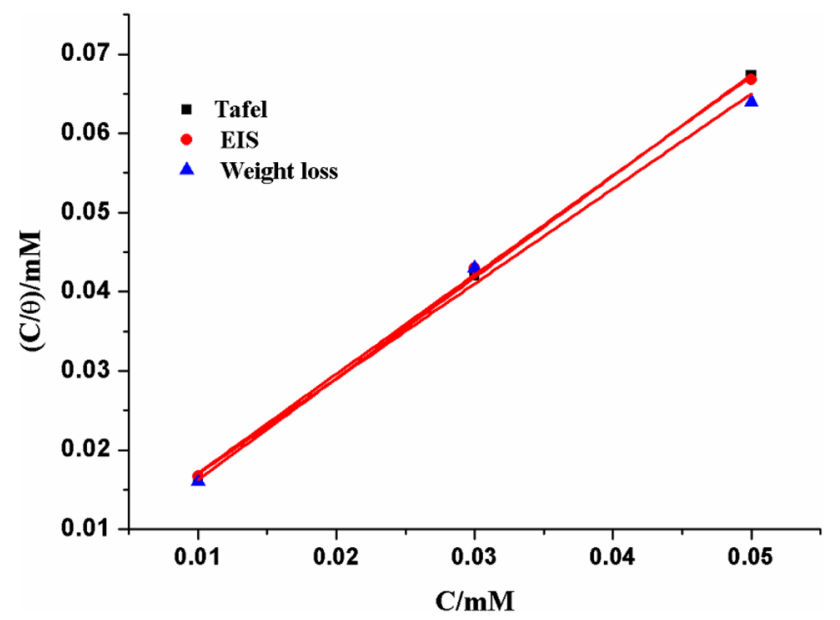

Fig. 8 Langmuir adsorption isotherms at $303 \mathrm{~K}$

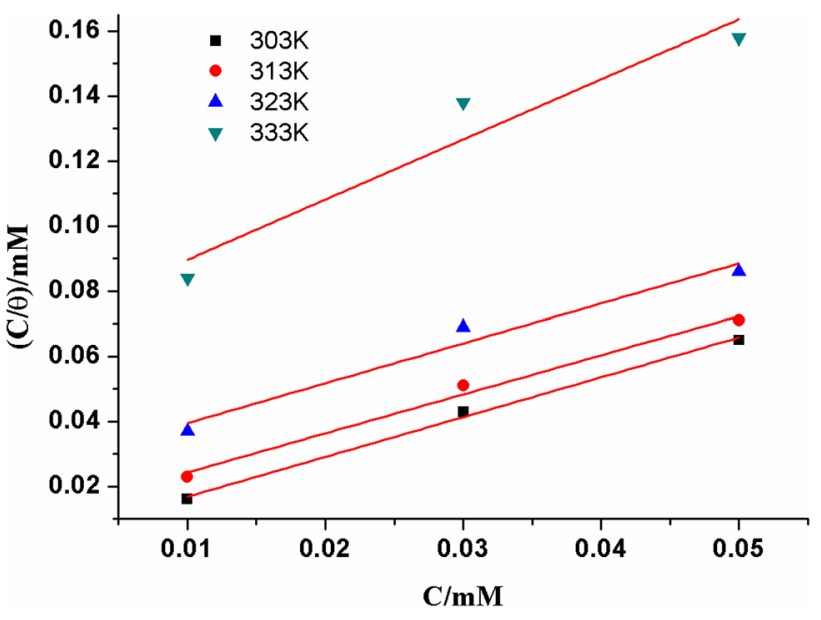

Fig. 9 Langmuir adsorption isotherm for disulfide at different temperatures

37 and $40 \mathrm{~kJ} \mathrm{~mol}^{-1}$. The $\Delta G_{\text {ads }}$ values between 20 and $40 \mathrm{~kJ} \mathrm{~mol}^{-1}$ suggest the comprehensive adsorption [35]. Thus, our inhibitor DSA undergoes comprehensive adsorption on steel. However, the values are close to $40 \mathrm{~kJ} \mathrm{~mol}^{-1}$, suggested a strong chemical interaction between inhibitor and steel surface. The change in enthalpy of adsorption process is calculated using the Van't Hoff equation as follows:

$\ln K_{\mathrm{ads}}=\frac{-\Delta H_{\mathrm{ads}}}{R T}+\frac{\Delta S_{\mathrm{ads}}}{R}+\ln \frac{1}{55.5}$

The value of entropy change of adsorption is calculated using the following thermodynamic equation

$\Delta G_{\text {ads }}=\Delta H_{\text {ads }}-T \Delta S_{\text {ads }}$

The value of $\Delta S_{\text {ads }}$ and $\Delta H_{\text {ads }}$ are obtained from slope and intercept of the plot of $\Delta G_{\text {ads }}$ versus $\mathrm{T}$, respectively

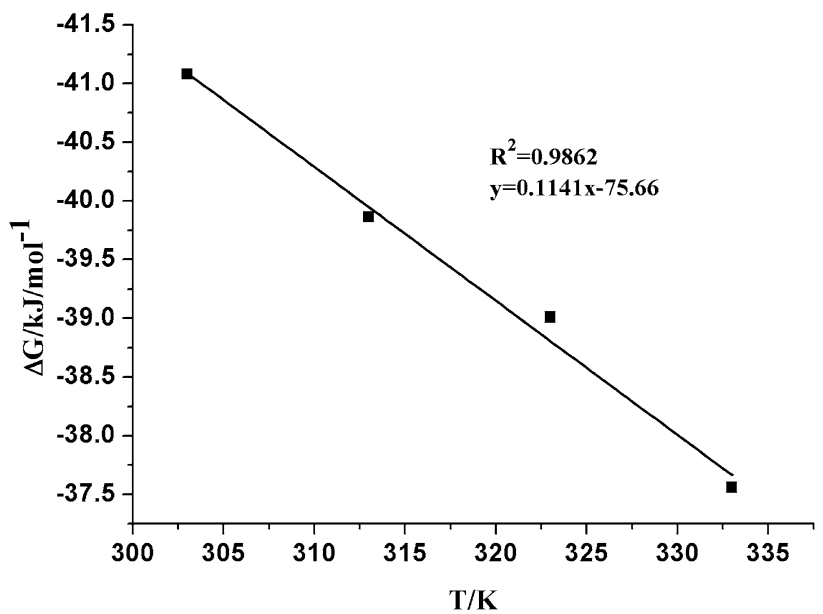

Fig. 10 Plot of $\Delta G$ versus $T$ 
(Fig. 10). This value of $\Delta S_{\text {ads }}$ and $\Delta H_{\text {ads }}$ are compatible with the values obtained from slope and intercept of a plot of $\ln K_{\text {ads }}$ verses $1 / T$ (Fig. 11). All the thermodynamic parameter values are tabulated in Tables 4 and 5 .

The values of enthalpy and entropy of adsorption obtained from both methods are in good agreement. The negative values of $\Delta H_{\text {ads }}$ illustrate that, the adsorption of the inhibitor on mild steel surface is an exothermic process [36].The adsorption enthalpy value for physisorption process is lower than $-40 \mathrm{~kJ} \mathrm{~mol}^{-1}$, but for chemisorption process it should be $-100 \mathrm{~kJ} \mathrm{~mol}^{-1}$ [37]. In present study, the values of enthalpy of adsorption lies in between -40 and $-100 \mathrm{~kJ} \mathrm{~mol}^{-1}$ (around $76 \mathrm{~kJ} \mathrm{~mol}^{-1}$ ) suggest comprehensive adsorption of DSA. The $\Delta S_{\text {ads }}$ values in the presence of inhibitor are positive, which illustrate that desorption of water molecules takes place from the metal/ solution interface during adsorption of DSA molecule on the steel surface [38].

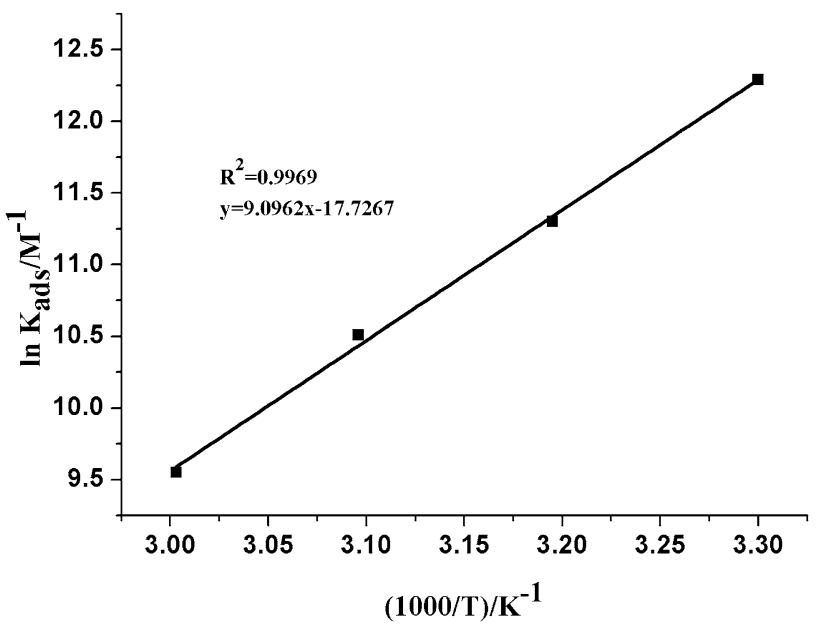

Fig. 11 Plot of $\ln K_{\text {ads }}$ versus $1 / T$

Table 5 Thermodynamic parameters obtained from weight loss method

\begin{tabular}{lrlll}
\hline $\begin{array}{l}\text { Tem- } \\
\text { perature } \\
(\mathrm{K})\end{array}$ & $K_{\text {ads }}\left(\mathrm{M}^{-1}\right)$ & $\begin{array}{l}-\Delta G_{\text {ads }} \\
\left(\mathrm{kJ} \mathrm{mol}^{-1}\right)\end{array}$ & $\begin{array}{l}-\Delta H_{\text {ads }} \\
\left(\mathrm{kJ} \mathrm{mol}^{-1}\right)\end{array}$ & $\begin{array}{l}\Delta S_{\text {ads }} \\
\left(\mathrm{J} \mathrm{mol}^{-1} \mathrm{~K}^{-1}\right)\end{array}$ \\
\hline 303 & 218,340 & 41.0 & 75.63 & 113.98 \\
313 & 81,103 & 39.9 & $75.66^{\mathrm{a}}$ & $114^{\mathrm{a}}$ \\
323 & 36,697 & 39.0 & & \\
333 & 14,061 & 37.6 & & \\
\hline
\end{tabular}

${ }^{\text {a }}$ Values obtained from $-\Delta G$ versus $T$
Table 4 Thermodynamic parameters obtained weight loss, EIS, and PDP methods

\begin{tabular}{llll}
\hline Technique & $R^{2}$ & $K_{\text {ads }} / \mathrm{M}^{-1}$ & $-\Delta G_{\text {ads }} / \mathrm{kJ} \mathrm{mol}^{-1}$ \\
\hline PDP & 0.9999 & 288,184 & 41.787 \\
EIS & 0.9983 & 220,750 & 41.115 \\
Weight loss & 0.9896 & 218,340 & 41.023 \\
\hline
\end{tabular}

\section{Surface morphology}

Morphology of mild steel specimens represented in Fig. 12 are the SEM images of the mild steel specimens after $4 \mathrm{~h}$ of immersion in $1 \mathrm{M} \mathrm{HCl}$ and $1 \mathrm{M} \mathrm{HCl}$ containing $0.05 \mathrm{mM}$ concentration of DSA. The morphology of the mild steel surface in uninhibited $1 \mathrm{M} \mathrm{HCl}$ reveals blisters of soluble corrosion product, with surface appears very uneven and highly damaged with a lot of debris (12a). The inhibited mild steel surface exhibits a less corrosive damage and the blisters are visibly reduced to produce a smooth surface (12b). It inferred that a protective layer of adsorbed DSA inhibitor is formed on the mild steel surface and hence prevents it from acid attack.

\section{Optical microscopic studies}

The corrosion morphology of uninhibited and inhibited mild steel specimens is also verified through optical microscopy Fig. 13. The optical microscopic images are taken from Olympus CX31microscopy with Motix camera provided with both trinocular and binocular lenses. The images are taken at $20 \times$ magnification with light illuminated at planepolarized- and cross-Nicols $\left(a^{\prime}\right)$ conditions. From the optical microscopic images, it can be seen that the uninhibited mild steel specimen shows remarkable amount of cracks and pits as in Fig. 13a. The inhibited mild steel describes a more even and uniform surface as in Fig. 13b. The morphology is clearly seen in the cross-Nicols $\left(a^{\prime}\right)$ condition at which the direction of illuminated light and image capturing is at a right angle to each other. Hence, optical photomicrographs clearly describe the corrosion damage of mild steel surface in the plane-polarized light condition.

\section{Quantum chemical studies}

Recent research on corrosion studies includes some advanced quantum chemical calculations. The theoretical data supports experimental findings and also assist in assigning a suitable mechanism for adsorption of inhibitor molecule. The inhibitor molecule undergoes adsorption to the metal surface via donor-acceptor interactions, which takes place between the molecular orbitals of inhibitor molecule and the vacant $d$-orbital of metal. These electronic 


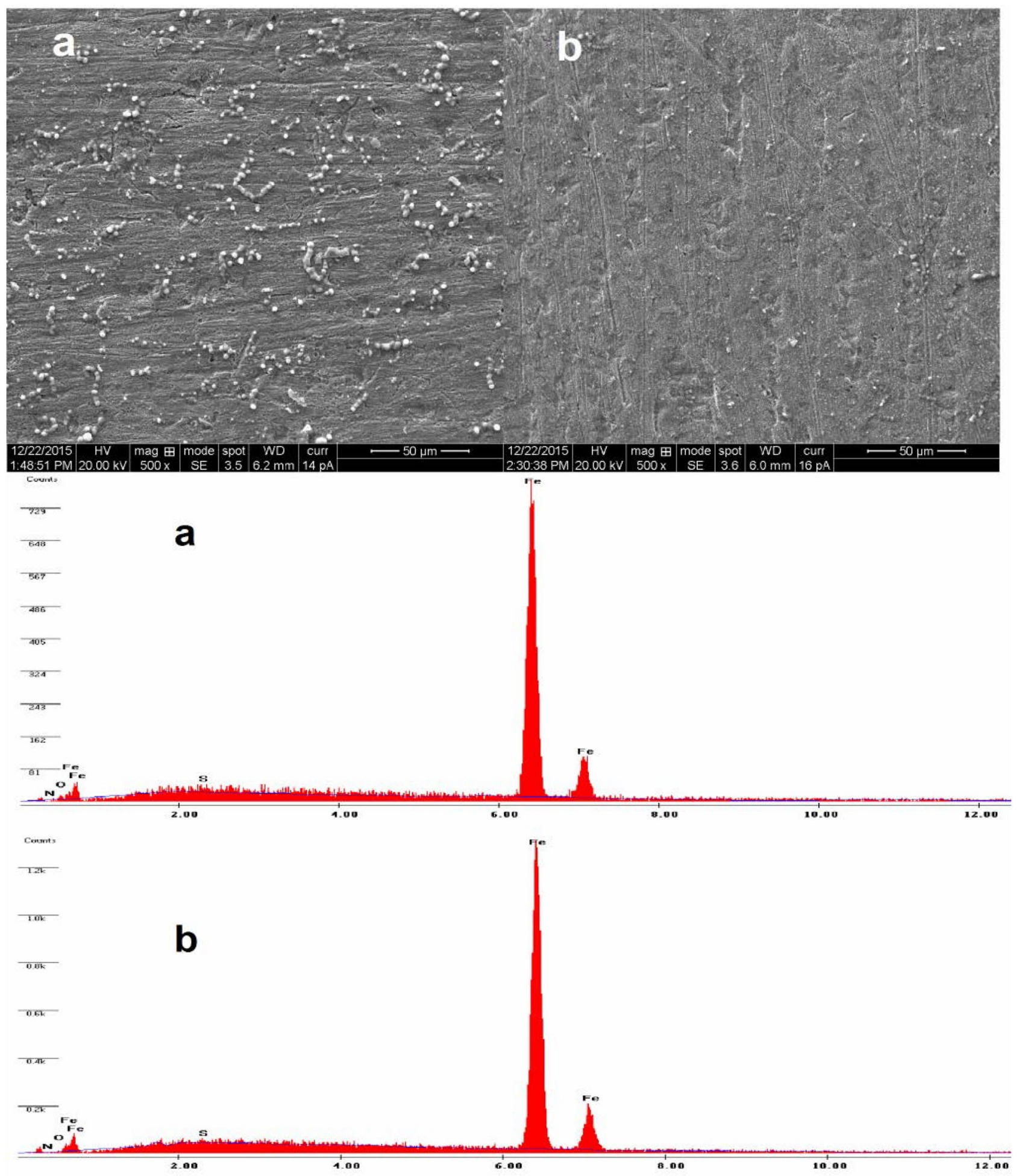

Fig. 12 SEM and EDX images of the mild steel surface after $4 \mathrm{~h}$ of immersion at $30^{\circ} \mathrm{C}$ : a $1 \mathrm{M} \mathrm{HCl}$, and b $1 \mathrm{M} \mathrm{HCl}+0.05 \mathrm{mM}$ disulfide

interactions can be related to the frontier molecular orbital (FMO). The FMOs are of two types: highest occupied molecular orbital (HOMO) and lower unoccupied molecular orbital (LUMO). The energy of these two FMOs decides the ability of inhibitor and the molecular energy gap $\Delta E=E_{\mathrm{LUMO}}-E_{\mathrm{HOMO}}$, is another important parameter which is used to depict the adsorption of inhibitor on metal surface. In this concern, quantum chemical parameters such 
Fig. 13 Optical microscopic images of mild steel surface after immersion at $30{ }^{\circ} \mathrm{C}(\mathbf{a}$, $\mathbf{a}^{\prime}$ are images of same plate generated for parallel and perpendicular direction of incident light radiation) in $1 \mathrm{M} \mathrm{HCl}$ and $\left(\mathbf{b}, \mathbf{b}^{\prime}\right)$ in $1 \mathrm{M} \mathrm{HCl}+0.05 \mathrm{mM}$ disulfide

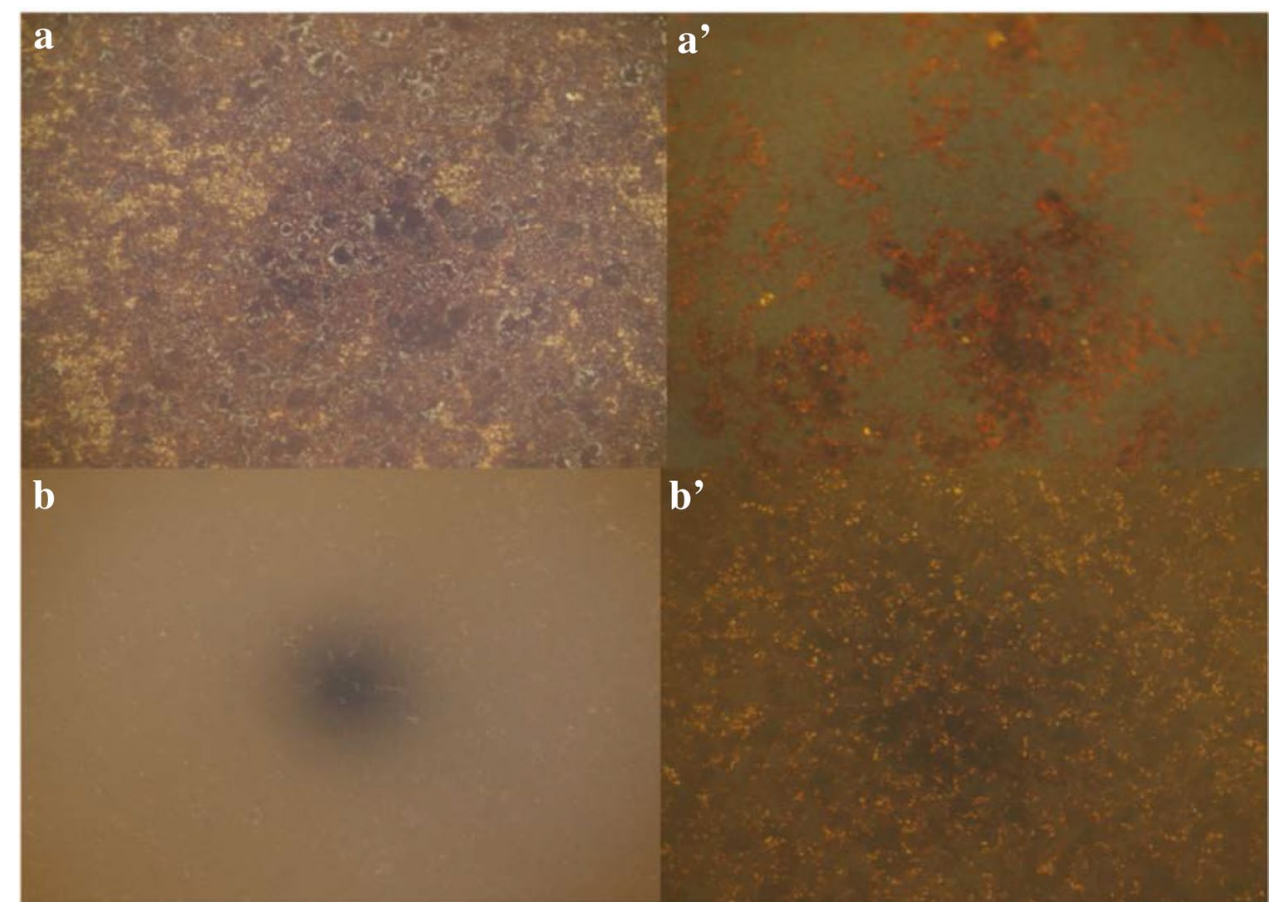

Table 6 Quantum chemical parameters for DSA molecule

\begin{tabular}{lllll}
\hline$E_{\mathrm{HOMO}}$ & $E_{\mathrm{LUMO}}$ & $\Delta E$ & $\begin{array}{l}\text { Dipole moment } \\
(\mu)\end{array}$ & $\mathrm{TNC}$ \\
\hline$-5.4586 \mathrm{eV}$ & $-1.5184 \mathrm{eV}$ & $3.9402 \mathrm{eV}$ & $2.403 \mathrm{D}$ & -2.38598 \\
\hline
\end{tabular}

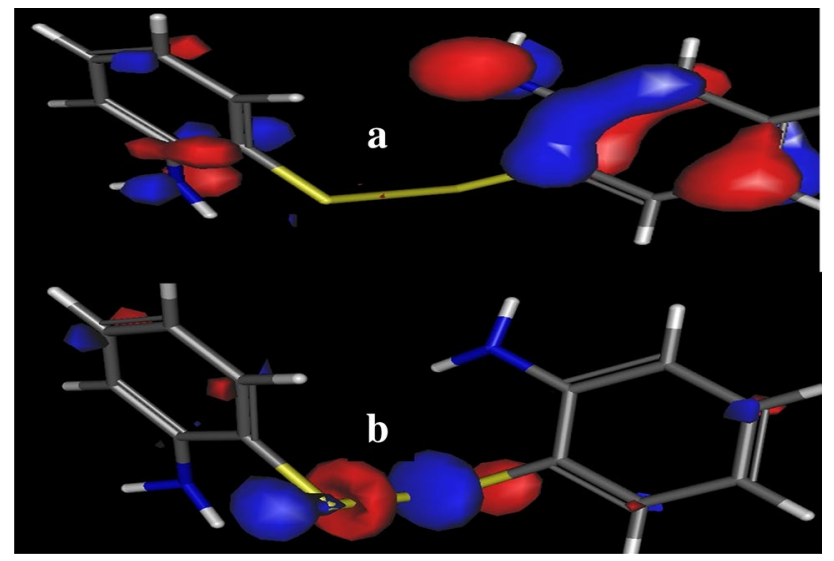

Fig. 14 Frontier molecular orbital distribution a $\mathrm{HOMO}$ and $\mathbf{b}$ LUMO disulfide

as $E_{\mathrm{LUMO}}, E_{\mathrm{HOMO}}$, energy gap $\Delta E$, dipole moment $(\mu)$ and total negative charge (TNC) were summarized in Table 6. Optimized geometric structures, as well as FMOs electron distributions, were represented in Fig. 14.
It is well known from literature that, a higher value of $E_{\mathrm{HOMO}}$ indicates electron-donating tendency of inhibitor towards steel. The lower value of $E_{\mathrm{LUMO}}$ indicates the back-bonding tendency of inhibitor. A higher value of $E_{\mathrm{HOMO}}$, lower value of $E_{\mathrm{LUMO}}$ and $\Delta E=E_{\mathrm{LUMO}}-E_{\mathrm{HOMO}}$ increases the inhibition efficiency of inhibitor [39]. By inspection of Fig. 14, it is clear that, HOMO is distributed over the entire aromatic ring including amine group. LUMO is located at the disulfide linkage a slight and negligible distribution on a few carbons of the aromatic ring. It is well documented in the literature that, excellent inhibitors are those which not only offer electrons to the unoccupied d-orbitals of the metal atom but have good tendency to accept and accommodate electrons in their unoccupied orbitals [40]. In the present inhibitor case, it utilizes its aromatic electron and lone pair electrons present on the nitrogen of amine group to adsorb on the steel and the feedback bond is formed utilizing disulfide linkage.

The dipole moment $(\mu)$ value of inhibitor is found to be 2.4, which favors its adsorption on steel. The Mulliken population is a good probe to locate adsorption sites present on inhibitor molecule. From the review of several kinds of literature, adsorption centers are negatively charged heteroatom and negatively charged carbon atoms of an aromatic ring. If the negative charges present on several atoms of an inhibitor molecule, the adsorption of inhibitor takes place in plane with the metal surface resulting in its even distribution $[41,42]$. The TNC value is another important parameter to quantify the adsorption centers present on a molecule. Higher the value of TNC for an inhibitor, larger is the charge 
Fig. 15 Pictorial representation of mechanism of action of disulfide

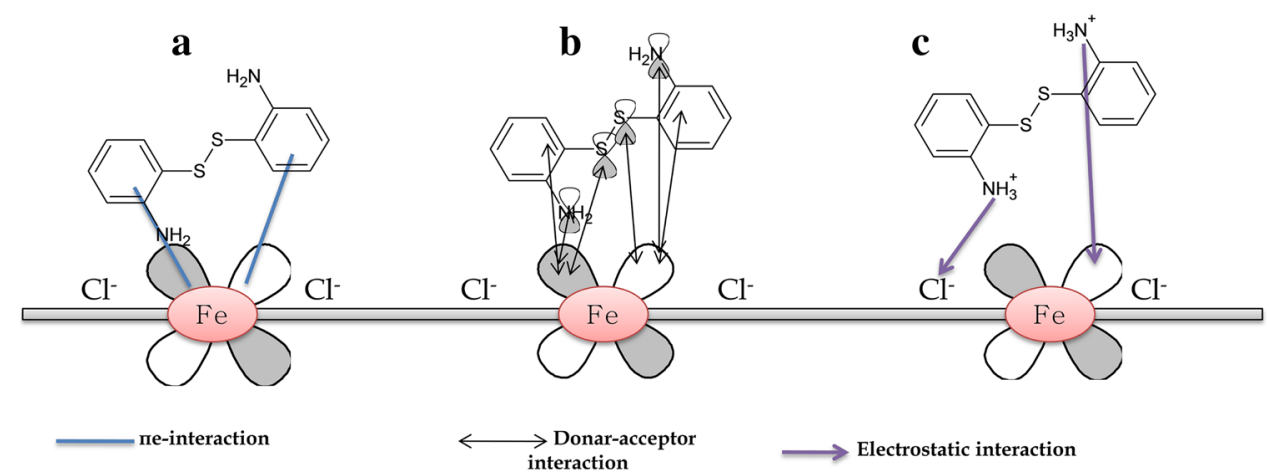

separation and hence the good number of adsorption sites is present on inhibitor [43]. In the present case, Mullikan charge distribution (Supplementary Table S1) and the TNC value revealed the presence of more number of adsorption site. The presence of more adsorption centers results in flat orientation of inhibitor molecule on the steel surface [44], thus form a layer of DSA inhibitor over steel surface and protect the steel from corrosive $\mathrm{HCl}$ medium.

\section{Inhibition mechanism}

The mechanism of inhibition is explained on the basis of mode of adsorption of inhibitor. Generally, the charge on the metal, chemical structure (electronic density at the donor site) of inhibitor, type of interaction between inhibitor and metal influence the adsorption process. The DSA inhibitor has electronegative donor atoms such as $\mathrm{N}, \mathrm{S}$ and $\pi$-electrons of the aromatic ring. These electron-rich donor atoms in addition with $\pi$-electrons of the aromatic ring favor adsorption of DSA inhibitors onto the mild steel surface. Since DSA undergoes comprehensive adsorption (involving both physisorption and chemisorption), the possible modes of interaction of DSA with the mild steel surface are: chemisorptions of DSA molecule, which may occur through sharing $\pi$-electrons of the aromatic ring (Fig. 15a) or by sharing of lone pair electrons of $\mathrm{N}$ and $\mathrm{S}$ atoms with the vacant d-orbital of iron atoms of steel surface through donor-acceptor interaction (Fig. 15b). The coordination tendency of iron towards these donor sites of inhibitor is responsible for the formation of the adsorptive film [44].

In $\mathrm{HCl}$ solution nitrogen containing compounds undergoes protonation to form protonated species. It is well known that, steel when kept in acid solution, carries a positive charge. Chloride ions from acid get adsorbed at the metal/ solution interface creating a negative charge at the electrode surface and thus favour the adsorption of protonated inhibitors. Hence, the protonated DSA has a tendency to adsorb on steel surface through electrostatic interaction and thus facilitating physical adsorption of inhibitor (Fig. 15c). Thus, formations of inhibitor film on steel either through physisorption or chemisorption or through both resulted in reduction of corrosion rate. As inhibitor concentration increases, it covers more corrosion active sites and thus results in higher inhibition efficiency.

\section{Conclusions}

The synthesized compound showed good inhibition property up to $75 \%$. The inhibition efficiency calculated from potentiodynamic polarization, EIS, weight loss measurements were in good agreement with each other. Adsorption studies showed that inhibitor follows Langmuir adsorption isotherm and thus formation of a monolayer of disulfide is expected on the steel surface. Thermodynamic properties indicated the comprehensive adsorption of disulfide on the steel surface. SEM and optical photomicrographs exhibited a good surface with less corrosion of mild steel in the presence of DSA compound.

Acknowledgements The authors are grateful to the Kuvempu University, Karnataka, India for providing lab facilities to carry out this work. M. R. Vinutha thanks the University Grant Commission, Government of India, New Delhi for providing BSR fellowship. Authors are thankful to Mr. Vinayak Bhat Department of Physics, Shri Madhwa Vadiraja Institute of Technology and Management, Bantakal, Udupi for assisting in quantum determination of the compounds.

Open Access This article is distributed under the terms of the Creative Commons Attribution 4.0 International License (http://creativeco mmons.org/licenses/by/4.0/), which permits unrestricted use, distribution, and reproduction in any medium, provided you give appropriate credit to the original author(s) and the source, provide a link to the Creative Commons license, and indicate if changes were made.

\section{References}

1. Murulana LC, Singh AK, Shukla SK, Kabanda MM, Ebenso EE (2012) Experimental and quantum chemical studies of some bis(trifluoromethyl-sulfonyl) imide imidazolium-based ionic 
liquids as corrosion inhibitors for mild steel in hydrochloric acid solution. Ind Eng Chem Res 51:13282-13299

2. Liu J, Yu W, Zhang J, Hu S, You L, Qjao G (2010) Molecular modeling study on inhibition performance of imidazolines for mild steel in $\mathrm{CO}_{2}$ corrosion. Appl Surf Sci 256:4729-4733

3. Hosseini MG, Ehteshamzadeh M, Shahrab T (2007) Protection of mild steel corrosion with Schiff bases in $0.5 \mathrm{M} \mathrm{H}_{2} \mathrm{SO}_{4}$ solution. Electrochim Acta 52:3680-3685

4. Gomez B, Likhhanova NV, Dominguez-Aguilar MA, Martinez Palou R, Vela A, Gazquez JL (2006) Quantum chemical study of the inhibitive properties of 2-pyridyl-azoles. J Phys Chem B 110:8928-8934

5. Prasanna MB, Praveen MB, Narayana H, Venkatesha TV, Tandon HC (2014) Ketosulfone drug as a green corrosion inhibitor for mild steel in acidic medium. Ind Eng Chem Res 53:8436-8444

6. Kabanda MM, Shukla SK, Singh AK, Murulana LC, Ebenso EE (2012) Electrochemical and quantum chemical studies on calmagite and fast sulphone black F dyes as corrosion inhibitors for mild steel in hydrochloric medium. Int J Electrochem Sci 7:8813-8831

7. Ameer MA, Khamis E, Al-Senani G (2000) Adsorption studies of the effect of thiosemicarbazides on the corrosion of steel in phosphoric acid. Adsorpt Sci Technol 18:177-194

8. Keles H, Keles M, Dehri I, Serindag O (2008) The inhibitive effect of 6-amino-m-cresol and its Schiff base on the corrosion of mild steel in 0.5 M HCI medium. Mater Chem Phys 112:173-179

9. Kliskic M, Radosevic J, Gudic S, Katalinic V (2000) Behaviour of Al-Sn alloy on the negative side of the open-circuit potential. J Appl Electrochem 30:823-827

10. Roy P, Sukul D (2015) Protein- surfactant aggregate as a potential corrosion inhibitor for mild steel in sulphuric acid: zein-SDS system. RSC Adv 5:1359-1365

11. Sherif EM, Park SM (2006) Inhibition of copper corrosion in acidic pickling solutions by $N$-phenyl-1,4-phenylenediamine. Electrochim Acta 51:4665-4673

12. Shibli SMA, Saji VS (2005) Co-inhibition characteristics of sodium tungstate with potassium iodate on mild steel corrosion. Corros Sci 47:2213-2224

13. Tang L, Mu G, Liu G (2003) The effect of neutral red on the corrosion inhibition of cold rolled steel in $1.0 \mathrm{M}$ hydrochloric acid. Corros Sci 45:2251-2262

14. Cao P, Gu R, Tian Z (2002) Electrochemical and surface-enhanced raman spectroscopy studies on inhibition of iron corrosion by benzotriazole. Langmuir 18:7609-7615

15. Deberry DW, Peyton GR, Clark WS (1984) Evaluation of corrosion inhibitors in $\mathrm{SO}_{2}$ scrubber solutions. Corros 40:250-256

16. Hunter R, Caira M, Stellenboom N (2006) Inexpensive, one-pot synthesis of unsymmetrical disulfides using 1-chlorobenzotriazole. J Org Chem 71:8268-8271

17. Kirihara M, Asai Y, Ogawa S, Noguchi T, Hatano A, Hirai Y (2007) Inexpensive one-pot synthesis of unsymmetrical disulfides using 1-chlorobenzotriazole. Synthesis 71:3286-3289

18. Sanz R, Aguado R, Pedrosa MR, Arnáiz F (2002) Selective and quantitative conversion of thiols to disulfides was effected by dimethyl sulfoxide under mild conditions catalyzed by dichlorodioxomolybdenum (VI). Synthesis 7:856-858

19. Bao M, Shimizu M (2003) $N$-Trifluoroacetyl arenesulfenamides are effective precursors for the synthesis of unsymmetrical disulfides and sulfenamides. Reactions of $N$-trifluoroacetyl arenesulfenamides with thiols and amines gave the desired products in high yields within short reaction times. Tetrahedron 59:9655-9659

20. Maurya CK, Mazumder A, Kumar A, Gupta PK (2016) The use of sodium in silica gel enables an efficient synthesis of symmetrical disulfanes from organic thiocyanates at room temperature. This protocol provides an attractive alternative to existing methods for the preparation of symmetrical disulfanes as it avoids the use of foul-smelling thiols. Synlett 27:409-411

21. Granovsky AA (2015) Code development and Intel/AMD specific optimization. Firefly version 8.1.1, build number 9295. Firefly Project, Moscow, Russia. http://classic.chem.msu.su/gran/firefly/ index.html

22. Schmidt MW, Baldridge KK, Boatz JA, Elbert ST, Gordon MS, Jensen JH, Koseki S, Matsunaga N, Nguyen KA, Su S, Windus TL, Dupuis M, Montgomery JA (1993) Execution of gamess begun 21: 01: 54 LT 10-jul-2006. J Comput Chem 14:1347-1363

23. Esmaili R, Nematollahi D (2013) Electrochemical method for the synthesis of disulfides of 2-(Benzo[d]thiazol(or oxazol)-2-ylamino)-5-morpholinobenzenethiol. J Org Chem 78:5018-5021

24. Jebakumar Immanuel Edison T, Sethuraman MG (2013) Electrochemical investigation on adsorption of fluconazole at Mild steel/ $\mathrm{HCl}$ acid interface as corrosion inhibitor. ISRN Electrochem 256086:8

25. Al-Sabagh AM, Kandil NGh, Ramadan O, Amer NM, Mansour R, Khamis EA (2011) Novel cationic surfactants from fatty acids and the corrosion inhibition efficiency for carbon steel pipe lines in $1 \mathrm{M} \mathrm{HCl}$. Egypt J Pet 20:47-57

26. Singh AK, Quraishi MA (2010) Effect of cefazolin on the corrosion of mild steel in $\mathrm{HCl}$ solution. Corros Sci 52:152-160

27. Yuan SJ, Pehkonen SO, Ting YP, Kang ET, Neoh KG (2008) Corrosion behavior of type 304 stainless steel in a simulated seawater-based medium in the presence and absence of aerobic pseudomonas NCIMB 2021 bacteria. Ind Eng Chem Res 47:3008-3020

28. Appa Rao BV, Chaitanya Kumar K (2014) Effect of hydrodynamic conditions on corrosion inhibition of $\mathrm{Cu}-\mathrm{Ni}(90 / 10)$ alloy in seawater and sulphide containing seawater using 1,2,3-benzotriazole. J Mater Sci Technol 30:65-76

29. Solmaz R, Kardas G, Culha M, Yazlcl B, Erbil M (2008) Investigation of adsorption and inhibitive effect of 2-mercaptothiazoline on corrosion of mild steel in hydrochloric acid media. Electrochim Acta 53:5941-5952

30. Baskar R, Kesavan D, Gopiraman M, Subramanian K (2013) Synthesis of novel photosensitive polymers for the protection of mild steel from acid corrosion. RSC Adv 3:17039-17047

31. Deng S, Li X, Fu H (2010) Nitrotetrazolium blue chloride as a novel corrosion inhibitor of steel in sulfuric acid solution. Corros Sci 52:3840-3846

32. Jeeva M, Prabhu GV, Boobalan MS, Rajesh C (2015) Interactions and inhibition effect of urea-derived Mannich bases on a mild steel surface in HCl. J Phy Chem C 11:22025-22043

33. Ekanem UF, Umoren SA, Udousoro II, Udoh AP (2010) Inhibition of mild steel corrosion in $\mathrm{HCl}$ using pineapple leaves-(Ananas comosus L.) extract. J Mater Sci 45:5558-5566

34. Noor EA (2009) Potential of aqueous extract of Hibiscus sabdariffa leaves for inhibiting the corrosion of aluminum in alkaline solutions. J Appl Electrochem 39:1465-1475

35. Gomma GK (1998) Corrosion inhibition of steel by benzotriazole in sulphuric acid. Mater Chem Phys 55:235-240

36. Martinez S, Stern I (2002) thermodynamic characterization of metal dissolution and inhibitor adsorption processes in the low carbon steel/mimosa tannin/sulfuric acid system. Appl Surf Sci 199:83-89

37. Gholami M, Danaee I, Maddahy MH, Rashvand Avei M (2013) Correlated ab initio and electroanalytical study on inhibition behavior of 2-mercaptobenzothiazole and its thiole-thione tautomerism effect for the corrosion of steel (API 5L X52) in sulphuric acid solution. Ind Eng Chem Res 52:14875-14889

38. Cruz J, Pandiyan Thangarasu, Garcia-Ochoa E (2005) A new inhibitor for mild carbon steel: electrochemical and DFT studies. J Electroanal Chem 583:8-16 
39. Cruz J, Martínez V, Genesca J, García-Ochoa E (2004) Experimental and theoretical study of 1-(2-ethylamino)-2-methylimidazoline as an inhibitor of carbon steel corrosion in acid media. $\mathrm{J}$ Electroanal Chem 566:111-121

40. Hasanov R, Sadikoglu M, Bilgic S (2007) Electrochemical and quantum chemical studies of some Schiff bases on the corrosion of steel in $\mathrm{H}_{2} \mathrm{SO}_{4}$ solution. Appl Surf Sci 253:3913-3921

41. Li W, He Q, Pei C, Hou B (2007) Experimental and theoretical investigation of the adsorption behaviour of new triazole derivatives as inhibitors for mild steel corrosion in acid media. Electrochim Acta 52:6386-6394

42. Eddy NO, Ebenso EE, Ibok UJ (2010) Adsorption, synergistic inhibitive effect and quantum chemical studies of ampicillin (AMP) and halides for the corrosion of mild steel in $\mathrm{H}_{2} \mathrm{SO}_{4}$. $\mathrm{J}$ Appl Electrochem 40:445-456
43. Tang Y, Yang X, Yang W, Wan R, Chen Y (2010) A preliminary investigation of corrosion inhibition of mild steel in $0.5 \mathrm{M} \mathrm{H}_{2} \mathrm{SO}_{4}$ by 2-amino-5-(n-pyridyl)-1,3,4-thiadiazole: polarization, EIS and molecular dynamics simulations. Corros Sci 52:1801-1808

44. Li X, Deng S, Fu H, Li T (2009) Adsorption and inhibition ef fect of 6-b enzylaminopurine on cold rolled steel in $1.0 \mathrm{M} \mathrm{HCl}$. Electrochim Acta 54:4089-4098

Publisher's Note Springer Nature remains neutral with regard to jurisdictional claims in published maps and institutional affiliations. 